\title{
Healing words
}

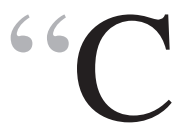
omplete remission," I explained to her, "is the disappearance of all signs of cancer in response to treatment." I had explained this to thousands of patients before, always emphasizing the word "signs." The fine print in oncology is that malignant cells may be lurking in dark corners, too few and far between for us to see with scans and routine bone marrow biopsies, which is why we carefully avoid pronouncing the cancer as "cured." Our goal is "remission," I would remind her. "Cure is a word we can use later on, after five years of remission."

She was one of the few patients who understood the fine line between these words. She was a former 9-1-1 operator. Communicating verbally, on the phone, without the help of a person's facial expression and nonverbal cues, she counselled patients and families, using her listening abilities to make decisions and her words to bring about healing and directing people to the next, often life-saving, steps. She saw herself as the suspension bridge between the medical community and public, as she remotely triaged heart attacks, strokes, trauma and the more nonemergent situations.

Believing her judgment to be wellinformed when it came to differentiating between emergencies and nonemergencies, she ignored her own vague symptoms of abdominal pain and generalized weakness the summer day she felt ill. Dehydration, she scoffed. Yet she found herself in the emergency department within 24 hours. She had called the help line that she herself had guided patients through for years, and was brought by ambulance to the nearest hospital.

I met her another 24 hours later. Blood counts had plummeted and budding lymph nodes appeared to be erupting across her body. Two more scans and a biopsy later, I sat down across from her and shared the diagnosis: Burkitt lymphoma/leukemia. One of the most aggressive and rapidly growing tumours, but also one of the most curable.

"What does this mean for me now?" She was always forward-looking.

"We need to start a multidrug intensive chemo regimen. You'll have to stay in hospital for 30 days during the first session. We need to monitor you,

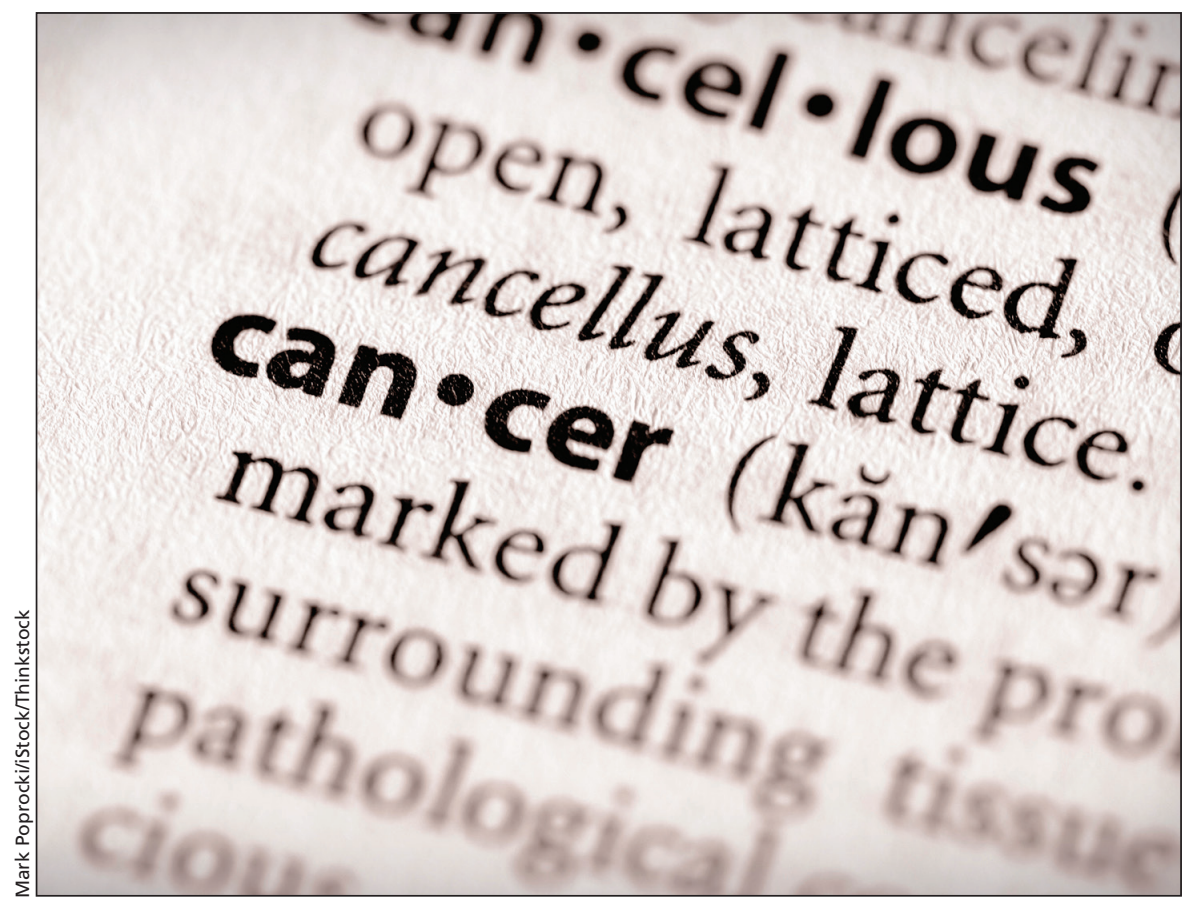

plus you need to be in a protected place because you'll be so vulnerable to infections."

She looked at me as if I might as well have told her that she would be dying in 30 days. She was 51 years old and living a full life with friends, hobbies and church. Every day thereafter, she would beg me to let her leave. I began to fear that she would leave against medical advice, and I promised I would do my best to help her make it through this suffocatingly boring isolation. I put on my most encouraging sideline cheering face and daily exclaimed to her how amazingly well she was doing. The chemo was working. Superbly. Magnificently. Gloriously.

She told me that the 20 minutes that we spent together every morning was the highlight of her day. She especially looked forward to the "adverb of the day." She called me "Dr. Adverb" and began writing the adverbs on the white dry-erase board in her room. The "adverb of the day" became an essential part of her Facebook blog, which she faithfully updated daily. Each adverb told her she would make it through this marathon, giving her the hope and stamina to keep focusing on the finish line.

One day on rounds, I looked at her patient message board - which serves as part to-do list, part motivator, part idea-tracker in those lonely rooms. "Hmm, I've used wonderfully, radically, beautifully, fantastically, supremely, astoundingly and terrifically. Today's word, then, is gladiferously."

"Is that a word, Doctor?"

"I made up a word just for you!" I took my job of providing the healing words to carry her through chemo as seriously as I did writing the orders for hyperfractionated cyclophosphamide, vincristine, doxorubicin, dexamethasone and rituximab. Thus, when I ran out of adverbs, I took the liberty of creating a few. The word game became the highlight not only of her day, but of mine as well.

We continued this game for the 
remaining seven cycles of chemo. Before each admission, she fought harder to stay out of the hospital, each toxicity wearing her down more. By cycle five, she would seriously tell me, "No more chemo. I can't take it - the fatigue, the neutropenic fevers. Besides, my blood counts are fine." We bargained, reducing doses, delaying cycles and concocting more adverbs, until finally she finished eight cycles.

I continue to see her in clinic, now
Words not only communicate ideas between people, they also create a new paradigm of thinking for ourselves. Remission is a good state in which to be but does not capture the deepest absence of disease, which she indeed did achieve: not only the standard criteria for complete remission, but also flow cytometry being negative for minimal residual disease and disappearance of the c-myc gene. She serendipitously had found a word to represent this state

\section{She called me "Dr. Adverb" The word game was the highlight of both our days.}

after two years of complete remission. I tell her, "Congratulations! You are in complete remission," as ecstatic as I am whenever I have such good news. For the first time, though, my patient responds by shaking her head. "Doctor, you created so many words for me. Now it is my turn to make up a word for you. I don't like the word remission. My word is submission."

I raise my eyebrows as she continues earnestly, "I realized that just like I submit to God, my leukemia is submitting to treatment. Just like we rebelliously cause havoc in the world, the tumour cells rebelliously run amok in my body. We don't have to call it 'cure.' I just don't want to be in 'remission' because it sounds so temporary - like the cancer is on hiatus but just biding its time for a comeback." I hardly have to remind her that the leukemia may be in submission partly because she submitted to the 30-day confinement and completed the eight cycles of chemotherapy. of even more order and well-being than medical textbook "remission."

Now, every time I see her, I continue to tell her, "You are in complete re - no, submission." She serves as a living reminder that sometimes, when I do my part, and with the help of chemotherapy and healing words, those dysfunctional cells do eventually respond and submit.

\section{Naveen Pemmaraju MD \\ Department of Leukemia \\ MD Anderson Cancer Center \\ Houston, Tex. \\ Elaine Chang MD \\ Department of Medicine \\ Baylor College of Medicine \\ Houston, Tex.}

This is a true story. The patient has given her consent for this story to be told. Her age was changed to help protect her privacy.

Correspondence to: Naveen Pemmaraju, npemmaraju@mdanderson.org;

Naveen Pemmaraju, @doctorpemm

CMAJ 2015. DOI:10.1503/cmaj.140743 